\title{
Evaluation of serum interleukin 6 and tumour necrosis factor alpha levels, and their association with various non-immunological parameters in renal transplant recipients
}

Gyanendra Kumar Sonkar ${ }^{1}$, PhD, Sangeeta Singh ${ }^{2}$, PhD, Satyendra Kumar Sonkar ${ }^{3}$, MD, Usha Singh ${ }^{4}$, MD, Rana Gopal Singh ${ }^{5}$, DM

\begin{abstract}
INTRODUCTION Renal transplant rejection involves both immunological and non-immunological factors. The objective of the present study was to investigate the association between immunological factors, such as serum interleukin 6 (IL-6) and tumour necrosis factor alpha (TNF- $\alpha$ ), and non-immunological parameters, such as age, serum creatinine $(\mathrm{SCr})$, creatinine clearance $(\mathrm{CrCl})$ and dyslipidaemia, in renal transplant recipients (RTRs).

METHODS This study included 90 RTRs and 90 healthy controls. Biochemical parameters, including serum IL- 6 and TNF- $\alpha$, were estimated using standard protocols. $\mathrm{CrCl}$ was calculated using the Cockroft-Gault equation, and the type of rejection was confirmed on biopsy. Student's $t$-test and univariate and multivariate analyses were performed using the Statistical Package for the Social Sciences for Windows version 15.

RESULTS The mean levels of serum IL- 6 and TNF- $\alpha$ were significantly higher in RTRs than in the control group $(p<0.001)$. These parameters were also found to be significantly different between the transplant rejection (TR) and transplant stable (TS) groups $(p<0.001)$. $\mathrm{CrCl}$ was significantly decreased in the TR group when compared to the TS group ( $p<0.001$ ). The two cytokines, IL- 6 and TNF- $\alpha$, correlated significantly with all metabolic parameters, such as $\mathrm{SCr}, \mathrm{CrCl}$ and dyslipidaemia. Multiple regression analysis showed that TNF- $\alpha$ and $\mathrm{CrCl}$ were the strongest predictors of IL-6.
\end{abstract}

CONCLUSION We conclude that immunological factors, as well as non-immunological factors such as $\mathrm{CrCl}$, SCr and dyslipidaemia, play important roles in the pathogenesis of graft rejection and renal graft dysfunction.

Keywords: creatinine clearance, interleukin 6, renal transplant recipients, total cholesterol, tumour necrosis factor alpha

\section{INTRODUCTION}

Renal transplant rejection involves both immunological (alloantigen-dependent) and non-immunological (alloantigenindependent) factors. Acute rejection (AR), which remains a major risk factor for the development of chronic rejection, ${ }^{(1)}$ involves a network of cytokines, growth factors and costimulatory molecules. ${ }^{(2)}$ Several cytokines such as interleukin 2, 5, 6 and 12 (IL-2, IL-5, IL-6, and IL-12, respectively), tumour necrosis factor alpha (TNF- $\alpha$ ) and interferon gamma are known to play important roles in the activation of immune responses that involve cytotoxic T-lymphocytes, natural killer (NK) cells and monocytes. ${ }^{(3)}$ Cytokines play an important role in allograft survival. ${ }^{(4)}$

A pleiotropic, multifunctional and proinflammatory cytokine with a molecular weight of $26 \mathrm{kD}$, IL-6 modulates both local and systemic immunity. ${ }^{(5,6)}$ Overproduction of IL-6 leads to the deposition of extracellular matrix proteins, development of inflammatory lesions and synthesis of acute phase proteins. ${ }^{(6-8)}$ While TNF- $\alpha$, which is also a cytokine like IL-6, is predominantly produced by macrophages, it can also be produced by monocytes and NK cells. TNF- $\alpha$ plays a central role in immune response. Studies have shown that serum TNF- $\alpha$ levels are increased in renal transplant recipients (RTRs) during rejection. ${ }^{(9-1)}$ Vascular permeability is enhanced by TNF- $\alpha$, thus leading to the infiltration of the graft by proinflammatory granulocytes. ${ }^{(12)}$ IL-6 and TNF- $\alpha$ can alter lipid metabolism and produce hyperlipidaemia, leading to atherosclerotic processes. ${ }^{(13,14)}$

A progressive rise in serum creatinine $(\mathrm{SCr})$, together with proteinuria, hypertension and a decline in glomerular filtration rate, are features characteristic of chronic allograft injury (CAI). ${ }^{(15)}$ Dyslipidaemia is an important non-immunological factor associated with the progression of kidney disease in transplant patients. ${ }^{(16)}$ TNF- $\alpha$ and IL- 6 are known to be significant predictors of the severity of coronary artery disease (CAD) in heart allograft recipients. ${ }^{(17)}$ The findings of these studies were considered in the design of our study, which aimed to investigate the association of the cytokines, serum IL- 6 and TNF- $\alpha$, as markers of allograft rejection in RTRs and the association of these immunological factors with nonimmunological factors such as age, SCr, creatinine clearance $(\mathrm{CrCl})$ and dyslipidaemia.

\footnotetext{
${ }^{1}$ Department of Biochemistry, King George's Medical University, Lucknow, ${ }^{2}$ Department of Pathology, Institute of Medical Sciences, Banaras Hindu University, Varanasi, ${ }^{3}$ Department of Medicine, King George's Medical University, Lucknow, ${ }^{4}$ Department of Pathology, ${ }^{5}$ Department of Nephrology, Institute of Medical Sciences, Banaras Hindu University, Varanasi, India

Correspondence: Dr Gyanendra Kumar Sonkar, Assistant Professor, Department of Biochemistry, King George's Medical University, Lucknow, India. gettwinklestar@rediffmail.com
} 
Table I. Demographics and clinical characteristics of patients.

\begin{tabular}{|c|c|c|c|c|c|c|}
\hline \multirow[t]{3}{*}{ Characteristic } & \multirow{3}{*}{$\begin{array}{l}\text { Control group } \\
\quad(n=90)\end{array}$} & \multicolumn{5}{|c|}{ Renal transplant recipients $(n=90)$} \\
\hline & & \multirow{2}{*}{$\begin{array}{l}\text { Transplant stable } \\
\qquad(\mathrm{n}=50)\end{array}$} & \multicolumn{4}{|c|}{ Transplant rejection } \\
\hline & & & $\begin{array}{c}\text { Total } \\
(n=40)\end{array}$ & $\begin{array}{l}\text { Acute rejection } \\
\quad(n=26)\end{array}$ & $\begin{array}{l}\text { Chronic allograft } \\
\text { injury }(n=14)\end{array}$ & p-value \\
\hline Age (yrs) & $30.40 \pm 8.04$ & $31.52 \pm 9.48$ & $33.35 \pm 7.35$ & $31.76 \pm 8.30$ & $36.28 \pm 4.23$ & NS \\
\hline $\mathrm{SCr}(\mathrm{mg} / \mathrm{dL})$ & $0.95 \pm 0.17$ & $1.16 \pm 0.21^{*}$ & $2.12 \pm 0.68^{*,+}$ & $1.64 \pm 0.17$ & $3.00 \pm 0.23$ & $<0.001$ \\
\hline $\mathrm{CrCl}\left(\mathrm{mL} / \mathrm{min} / 1.73 \mathrm{~m}^{2}\right)$ & $85.00 \pm 16.09$ & $79.37 \pm 14.33$ & $45.76 \pm 13.06^{*,+}$ & $54.00 \pm 7.37$ & $30.48 \pm 3.56$ & $<0.001$ \\
\hline \multicolumn{7}{|l|}{ Cytokine (pg/mL) } \\
\hline Serum IL-6 & $7.51 \pm 2.63$ & $8.96 \pm 3.96$ & $47.80 \pm 20.10^{*,+}$ & $36.15 \pm 11.66$ & $69.42 \pm 12.95$ & $<0.001$ \\
\hline Serum TNF- $\alpha$ & $6.62 \pm 2.57$ & $13.24 \pm 3.33^{*}$ & $47.65 \pm 26.85^{*,+}$ & $31.53 \pm 5.89$ & $77.57 \pm 24.64$ & $<0.001$ \\
\hline \multicolumn{7}{|l|}{ Lipid profile (mg/dL) } \\
\hline TC & $167.11 \pm 30.07$ & $135.20 \pm 14.26^{*}$ & $161.85 \pm 28.76^{\dagger}$ & $150.69 \pm 28.64$ & $182.57 \pm 14.40$ & 0.01 \\
\hline $\mathrm{HDL}$ & $46.37 \pm 7.37$ & $43.56 \pm 8.89$ & $37.65 \pm 5.32^{*, \neq}$ & $38.53 \pm 4.90$ & $36.00 \pm 6.05$ & NS \\
\hline LDL & $103.76 \pm 25.60$ & $75.48 \pm 12.15^{*}$ & $99.75 \pm 26.70^{+}$ & $89.30 \pm 25.86$ & $119.14 \pm 15.64$ & 0.01 \\
\hline
\end{tabular}

Data is presented as mean \pm standard deviation.

${ }^{*} p<0.001$ vs. control group. ${ }^{\dagger} p<0.001$ vs. TS group. ${ }^{\ddagger} p<0.01$ vs. TS group. ${ }^{\S} p$-values for AR group vs. CAI group.

$\mathrm{CrCl}$ : creatinine clearance; HDL: high-density lipoprotein; IL-6: interleukin 6; LDL: low-density lipoprotein; NS: not significant; SCr: serum creatinine; SD: standard deviation; TC: total cholesterol; TNF- $\alpha$ : tumour necrosis factor alpha

\section{METHODS}

In a three-year period from January 2008 to December 2010, a total of 180 subjects were enrolled in this study. The study included 90 RTRs (mean age $32.33 \pm 8.55$ years) and 90 unrelated healthy controls (mean age $30.40 \pm 8.04$ years). The RTRs were recruited from the inpatient and outpatient services at the Department of Nephrology, Institute of Medical Sciences, Banaras Hindu University, Varanasi, India, and the unrelated healthy controls were age- and sex-matched staff/employees from our institute. Among the 90 RTRs, 50 were transplant stable (TS) with a mean age of $31.52 \pm 9.48$ years, and 40 experienced transplant rejection (TR) and had a mean age of $33.35 \pm 7.35$ years. The TR group included 26 patients with $\mathrm{AR}$ and 14 with CAI. All RTRs were maintained on triple immunosuppressive therapy with cyclosporine $A$, azathioprine and prednisone. The mean time period from the day of transplantation to the day of transplant rejection was $20.15 \pm 8.80$ (range 6-36) months. AR was defined based on clinical criteria, elevation of $\mathrm{SCr}$, reduction in urine output and response to antirejection therapy, and confirmed on biopsy. CAI was defined based on a decline in renal function for at least three months after transplantation, and was confirmed on biopsy (features of tubular atrophy, interstitial fibrosis, arteriosclerosis and glomerulosclerosis were observed). Patients with CAI due to post-transplant hypertension, recurrent disease and drug toxicity were excluded from the study. Informed consent was obtained from all enrolled patients and the study was approved by the ethical committee of the institute. This study adhered to the principles of the Declaration of Helsinki. ${ }^{(18)}$

Blood samples were taken on the day of biopsy, and the serum separated and stored at $-70^{\circ} \mathrm{C}$ for batch analysis. Serum IL-6 and serum TNF- $\alpha$ were assayed using enzyme-linked immunosorbent assay kits (Beckman Coulter Inc, Marseille, France), following the manufacturer's instructions. Samples were processed in a blinded analysis and the results were correlated with clinical and histological findings. SCr, total cholesterol (TC), high-density lipoprotein (HDL) and lowdensity lipoprotein (LDL) levels were assayed using standard methodology. $\mathrm{CrCl}$ was calculated using the Cockroft-Gault equation. ${ }^{(19)}$ All biopsies were reviewed by a renal pathologist, and rejections that were confirmed on biopsy were classified according to the Banff ' 05 criteria. ${ }^{(20)}$

Data was reported as mean \pm standard deviation. Statistical analysis was performed using the Statistical Package for the Social Sciences for Windows version 15 (SPSS Inc, Chicago, IL, USA). Student's t-test was used to compare the means of different groups and ascertain significance. Univariate analysis was used to study the relationship between the variables. Multiple regression analysis was used to determine the independent factors affecting dependent variables. A p-value of $<0.05$ was considered statistically significant.

\section{RESULTS}

Age, taken as a demographic parameter, showed no significant difference among the various groups (Table I). In the RTRs, the metabolic parameters $\mathrm{SCr}$ and $\mathrm{CrCl}$ were significantly raised and lowered, respectively, when compared to the control group. Although the SCr of the TS group was within normal limits, it was still slightly higher than that of the control group. SCr was highest in the TR group, with significantly higher values in patients with CAl than those with AR. $\mathrm{CrCl}$ was significantly lowered in the RTRs when compared to the control group. Although $\mathrm{CrCl}$ in the TS and control groups did not show significant variation, the variation seen was greater than that in the TR group. Within the TR group, $\mathrm{CrCl}$ was significantly decreased in patients with CAI when compared to those with AR.

The level of the two cytokines (i.e. serum IL-6 and serum TNF- $\alpha$ ) evaluated in this study were higher in the RTRs than the control group. The levels of both serum IL- 6 and serum 
Table II. Correlation between immunological and nonimmunological factors in renal transplant recipients.

\begin{tabular}{lccccc}
\hline \multirow{2}{*}{$\begin{array}{l}\text { Non-immunological } \\
\text { factor }\end{array}$} & \multicolumn{4}{c}{ Immunological factor } \\
\cline { 2 - 3 } & \multicolumn{2}{c}{ Serum IL-6 } & & \multicolumn{2}{c}{ Serum TNF- $\alpha$} \\
\cline { 2 - 3 } \cline { 5 - 6 } & 0.23 & 0.12 & & 0.21 & 0.16 \\
\hline Age & 0.89 & $<0.001$ & & 0.92 & $<0.001$ \\
SCr & -0.83 & $<0.001$ & & -0.77 & $<0.001$ \\
CrCl & 0.65 & $<0.001$ & & 0.61 & $<0.001$ \\
TC & -0.35 & 0.02 & & -0.39 & 0.01 \\
HDL & 0.65 & $<0.001$ & & 0.60 & $<0.001$ \\
\hline
\end{tabular}

${ }^{*} \mathrm{p}$-value $<0.05$ was considered statistically significant.

$\mathrm{CrCl}$ : creatinine clearance; HDL: high-density lipoprotein; IL-6: interleukin 6;

LDL: low-density lipoprotein; r: correlation coefficient; SCr: serum creatinine;

TC: total cholesterol; TNF- $\alpha$ : tumour necrosis factor alpha

TNF- $\alpha$ were significantly elevated in patients from the TR group when compared to those from the TS and control groups. However, when the cytokine levels were compared between the TS and control groups, only serum TNF- $\alpha$ was significantly elevated in the TS group. When the difference between the cytokine levels of patients with AR and those with CAI were analysed, both IL- 6 and TNF- $\alpha$ were found to be higher in patients with CAI (Table I).

The lipid profile parameters evaluated in our study were TC, HDL and LDL. The levels of all these parameters were lower in the RTRs than in the control group. Similar trends were observed when the RTRs were split into TS and TR groups and the respective group's lipid profile parameters were compared with the control group. When compared to the TS and control groups, the TR group had a significantly lower HDL level, while both TC and LDL levels were within normal limits. There was a greater reduction in HDL level in patients with CAl than in those with AR, although the difference was not significant (Table I).

In the RTRs, univariate analysis showed that serum IL-6 and TNF- $\alpha$ levels correlated significantly with metabolic parameters and dyslipidaemia (Table II). Multiple linear regression analysis was performed using all significant factors identified on univariate analysis so as to account for the influence of any confounding factors. The model predicted $87 \%\left(R^{2}=0.93\right)$ of variance for serum IL-6 on the basis of these factors $(p<0.001)$. Serum TNF- $\alpha(\beta=0.587, p=0.001)$ and $\mathrm{CrCl}(\beta=0.308, p=0.03)$ were the strongest predictors of serum IL-6, while the other variables were not (Table III).

\section{DISCUSSION}

Renal allograft rejection involves a network of cytokines, growth factors and co-stimulatory molecules. ${ }^{(2)}$ Several cytokines play an important role in the activation of immune responses. Our study showed a significant increase in the level of cytokines in RTRs, with both serum IL- 6 and TNF- $\alpha$ levels being significantly higher than that in the control group. In our study, the mean serum IL-6 level in the control group was
Table III. Multiple regression analysis for predictors of serum creatinine in renal transplant recipients.

\begin{tabular}{lcccc}
\hline \multirow{2}{*}{$\begin{array}{l}\text { Non-immunological } \\
\text { factor }\end{array}$} & \multicolumn{2}{c}{$\begin{array}{c}\text { Unstandardised } \\
\text { coefficients }\end{array}$} & \multirow{2}{*}{$\begin{array}{c}\text { Standardised } \\
\text { coefficient } \boldsymbol{\beta}\end{array}$} & p-value* \\
\cline { 2 - 3 } & $\mathbf{B}$ & SE & & \\
\hline Age & 0.204 & 0.177 & 0.073 & 0.28 \\
TNF- $\alpha$ & 0.561 & 0.157 & 0.587 & 0.001 \\
SCr & 0.887 & 7.954 & 0.025 & 0.91 \\
CrCl & -0.337 & 0.151 & 0.308 & 0.03 \\
TC & 0.118 & 0.085 & 0.126 & 0.17 \\
HDL & 0.152 & 0.215 & 0.051 & 0.49 \\
\hline
\end{tabular}

Note: Age, serum interleukin 6, glomerular filtration rate, total cholesterol, high-density lipoprotein and low-density lipoprotein were taken as independent variables. Low-density lipoprotein reached tolerance limit zero.

* p-value < 0.05 was considered statistically significant. $\mathrm{CrCl}$ : creatinine clearance; HDL: high-density lipoprotein; SCr: serum creatinine; SE: standard error; TC: total cholesterol; TNF- $\alpha$ : tumour necrosis factor alpha

$7.51 \pm 2.63 \mathrm{pg} / \mathrm{mL}$. Similarly, studies by Waiser et $\mathrm{al}^{(5)}$ and Kamimura et al ${ }^{(21)}$ found slightly lower levels of IL- 6 in controls, with reported mean values of $3.5 \pm 1.1 \mathrm{pg} / \mathrm{mL}$ and $0.24 \pm 0.05 \mathrm{pg} / \mathrm{mL}$, respectively. We also found that the elevation of serum TNF- $\alpha$ was significantly higher in both the TS and TR groups. This finding is consistent with other studies, which reported significantly lower serum TNF- $\alpha$ levels in controls than in transplant recipients experiencing organ rejection. . $9,10,22)^{-1}$

We postulate that injury to the endothelium might trigger the release of IL- 6 in RTRs. A German study reported that when compared to controls, both the levels of serum IL-6 in patients undergoing episodes of rejection and the levels of IL- 6 in biopsy tissues of kidneys undergoing rejection were elevated. ${ }^{(5)}$ This increase in IL-6 could be the result of increased activation of nuclear factor-kappa B, which is an inducible transplantation factor essential for the activation of several important inflammatory cytokine genes such as the IL- 6 and IL- 8 genes. ${ }^{(23,24)}$

Lipid abnormalities are very common in patients undergoing rejection, and hyperlipidaemia or dyslipidaemia is an important non-immunological risk factor for the rejection of grafts. High cholesterol, high LDL and elevated triglycerides have been reported in RTRs, before and after transplant. ${ }^{(25-28)}$ The elevation of cytokines and lipids indicates that RTRs are not only characterised by persistent immune alloactivation, but also by lipid metabolism disorders. In our study, the serum IL-6, TNF- $\alpha$, TC and LDL levels of patients with CAI were significantly higher than those in patients with AR.

Lipid levels are modulated by various mechanisms. ${ }^{(29)}$ Reports suggest that oxidised LDL may lead to increased production of proinflammatory cytokines and chemokines by macrophages and the endothelium. ${ }^{(30,31)}$ A study by Gullestad et al on the role of IL-6 in heart allograft CAD reported an increase in IL- 6 and LDL in patients with transplant CAD. ${ }^{(22)}$ In that study, the authors also showed that 
heart transplant patients with coronary dysfunction leading to heart allograft rejection have lower HDL levels, and higher TC and LDL levels than controls and patients with stable allografts. These findings are similar to that of our study on RTRs. We also found lower HDL levels, and higher TC and LDL levels in the TR group when compared to the TS group. Gullestad et al further reported an inverse correlation between HDL level and the levels of TNF- $\alpha$ and IL- 6 in their cohort of patients with or without allograft rejection,(22) which is similar to what was observed in our patients with or without transplant rejection.

A complex interrelation exists between cytokines and lipids. Studies have suggested that IL-6 may cause an increase in circulating lipid levels, probably through a decrease in peripheral lipoprotein lipase. ${ }^{(32,33)}$ In our study, HDL levels showed negative significant correlation with IL- 6 and TNF- $\alpha$, and were higher in the control and TS groups than in the TR group. During graft rejection, endothelium activation leads to the expression of adhesion molecules such as intercellular adhesion molecule 1, vascular cell adhesion molecule 1 and E-selectin. ${ }^{(34,35)}$ HDL disrupts the sphingosine kinase signalling pathway, resulting in the inhibition of the endothelium, which protects against the formation of atherosclerotic plaques in the blood vessels of the graft. $^{(36)}$

Endothelium-derived cytokines play an important role in several diseases, including atherosclerosis, graft rejection, asthma, vasculitis and sepsis. ${ }^{(37)}$ Chen et al suggested that TNF- $\alpha$ might be a potent regulator of lipid metabolism. ${ }^{(38)}$ Kario et al showed that a close relationship between high lipoprotein levels and IL- 6 is present in haemodialysis patients. ${ }^{(39)}$ IL-6 is responsible for increased hepatic production of fatty acids, triglycerides and cholesterol. ${ }^{(40)}$ Our finding that hypercholesterolaemia is an important risk factor for renal graft rejection is in agreement with the study by Swan. ${ }^{(41)}$ The elevation of serum IL-6 and TNF- $\alpha$ levels in RTRs therefore appears to be associated with dyslipidaemia. In our study, we obtained a negative significant correlation between IL- 6 and TNF- $\alpha$ levels, and $\mathrm{CrCl}$, thus indicating that these cytokines are associated with declining renal function. Similar results were also reported by other studies on patients with renal transplant rejection and chronic renal failure. ${ }^{(42,43)}$

In conclusion, immunological factors, as well as nonimmunological factors such as $\mathrm{SCr}, \mathrm{CrCl}$ and dyslipidaemia, play important roles in renal graft dysfunction and the pathogenesis of graft rejection.

\section{REFERENCES}

1. Boratyńska $M$, Banasik $M$, Watorek $E$, et al. Influence of hypercholesterolemia and acute graft rejection on chronic nephropathy development in renal transplant recipient. Transplant Proc 2003; 35:2209-12.

2. Malan Borel I, Racca A, Garcia MI, et al. Gammadelta T cells and interleukin-6 levels could provide information regarding the progression of human renal allograft. Scand J Immunol 2003; 58:99-105.

3. Amirzargar A, Lessanpezeshki $M$, Fathi $A$, et al. TH1/TH2 cytokine analysis in Iranian renal transplant recipients. Transplant Proc 2005; 37:2985-7.

4. Salomon B, Bluestone JA. Complexities of CD28/B7: CTLA-4 costimulatory pathways in autoimmunity and transplantation. Annu Rev Immunol 2001; 19:225-52.

5. Waiser J, Budde K, Katalinic A, et al. Interleukin-6 expression after renal transplantation. Nephrol Dial Transplant 1997; 12:753-9.

6. Pawlik A, Domanski L, Rozanski J, et al. The cytokine gene polymorphisms in patients with chronic kidney graft rejection. Transpl Immunol 2005; 14:49-52.

7. Kishimoto T, Akira S, Narazaki M, Taga T. Interleukin- 6 family of cytokines and gp130. Blood 1995; 86:1243-54.

8. Boratyńska M, Klinger M, Szyber P, Patrzalek D, Polak K. Interleukin-6 in chronic renal allograft rejection: influence of nonimmunologic risk factors. Transplant Proc 2001; 3:1215-7.

9. Bubnova LN, Kabakov A, Serebrianaya N, Ketlinky S. Interleukin-1 beta and tumor necrosis factor-alpha serum levels in renal allograft recipients. Transplant Proc 1992; 24:2545.

10. Hoffmann MW, Wonigeit K, Steinhoff G, et al. Production of cytokines (TNF-alpha, IL-1-beta) and endothelial cell activation in human liver allograft rejection. Transplantation 1993; 55:329-35.

11. Dörge SE, Roux-Lombard P, Dayer JM, et al. Plasma levels of tumor necrosis factor (TNF) and soluble TNF receptors in kidney transplant recipients. Transplantation 1994; 58:1000-8.

12. Heidenreich S, Lang D, Tepel M, Rahn KH. Monocyte activation for enhanced tumour necrosis factor-alpha and interleukin 6 production during chronic renal allograft rejection. Transpl Immunol 1994; 2:35-40.

13. Bukan N, Sancak B, Pasaoglu H, et al. Serum homocysteine, lipoprotein (a), tumour necrosis factor-alpha, total cholesterol and triglyceride levels in hemodialysis patients. Turkiye Klinikleri J Med Sci 2004; 24:435-9.

14. Borazan A, Ustün $\mathrm{H}$, Ustundag $\mathrm{Y}$, et al. The effects of peritoneal dialysis and hemodialysis on serum tumor necrosis factor-alpha, interleukin-6, interleukin-10 and C-reactive-protein levels. Mediators Inflamm 2004; 13:201-4.

15. Vanikar AV, Trivedi HL. Chronic rejection: an enduring enigma of transplantation biology. Transplant Proc 2007; 39:773-8.

16. Fernández Fresnedo G, Sánchez Plumed J, Arias M, Del Castillo Caba D, López Oliva MO. [Progression factor in chronic kidney disease. Non-immunological mechanism]. Nefrolgia 2009; 29 Suppl 1:16-24. Spanish.

17. Gotsman I, Stabholz A, Planer D, et al. Serum cytokine tumor necrosis factoralpha and interleukin- 6 associated with the severity of coronary artery disease: indicators of an active inflammatory burden? Isr Med Assoc J 2008; 10:494-8.

18. Shepherd DA. The 1975 Declaration of Helsinki and consent. Can Med Assoc J 1976; 115: 1191-2.

19. Cockcroft DW, Gault MH. Prediction of creatinine clearance from serum creatinine. Nephron 1976; 16:31-41.

20. Solez K, Colvin RB, Racusen LC, et al. Banff '05 Meeting Report: differential diagnosis of chronic allograft injury and elimination of chronic allograft nephropathy ('CAN'). Am J Transplant 2007; 7:518-26.

21. Kamimura MA, Draibe SA, Dalboni MA, et al. Serum and cellular interleukin-6 in haemodialysis patients: relationship with energy expenditure. Nephrol Dial Transplant 2007; 22:839-44.

22. Gullestad L, Simonsen S, Ueland T, et al. Possible role of proinflammatory cytokines in heart allograft coronary artery disease. Am J Cardiol 1999; 84:999-1003.

23. Denk A, Goebeler M, Schmid S, et al. Activation of NF-kappa B via the Ikappa B kinase complex is both essential and sufficient for proinflammatory gene expression in primary endothelial cells. J Biol Chem 2001; 276:28451-8.

24. Wei JF, Zheng SS. NF-kappa B in allograft rejection. Hepatobiliary Pancreat Dis Int 2003; 2:180-3.

25. Moore R, Thomas D, Morgan E, et al. Abnormal lipid and lipoprotein profiles following renal transplantation. Transplant Proc 1993; 25:1060-1.

26. Hernández E, Praga M, Alamo C, et al. Lipoprotein(a) and vascular access survival in patients on chronic hemodialysis. Nephron 1996; 72:145-9.

27. Shoji T, Nishizawa Y, Kawagishi T, et al. Intermediate-density lipoprotein as an independent risk factor for aortic atherosclerosis in hemodialysis patients. J Am Soc Nephrol 1998; 9:1277-84. 
28. Ramezani M, Einollahi B, Ahmadzad-Asl M, et al. Hyperlipidemia after renal transplantation and its relation to graft and patient survival. Transplant Proc 2007; 39:1044-7.

29. Jovinge $S$, Hamsten $A$, Tornvall $P$, et al. Evidence for a role of tumor necrosis factor alpha in disturbances of triglyceride and glucose metabolism predisposing to coronary heart disease. Metabolism 1998; 47:113-8.

30. Terkeltaub R, Banka CL, Solan J, et al. Oxidized LDL induces monocyte cell expression of interleukin-8, a chemokine with T-lymphocyte chemotactic activity. Arterioscler Thromb 1994; 14:47-53.

31. Jovinge S, Ares MP, Kallin B, Nilsson J. Human monocytes/macrophages release TNF-alpha in response to Ox-LDL. Arterioscler Thromb Vasc Biol 1996; 16:1573-9.

32. Fernández-Real JM, Broch M, Vendrell J, Rieart W. Interleukin-6 gene polymorphism and lipid abnormalities in healthy subjects. J Clin Endocrinol Metab 2000; 85:1334-9.

33. Greenberg AS, Nordan RP, McIntosh J, et al. Interleukin 6 reduces lipoprotein lipase activity in adipose tissue of mice in vivo and in 3T3-L1 adipocytes: a possible role for interleukin 6 in cancer cachexia. Cancer Res 1992; 52:4113-6.

34. Springer TA. Adhesion receptors of the immune system. Nature 1990; 346:425-34.

35. Vadas MA, Gamble JR. Endothelial adhesion molecules in atherogenesis. A concerto or a solo? Circ Res 1996; 79:1216-7.
36. Xia P, Vadas MA, Rye KA, Barter PJ, Gamble JR. High Density Lipoproteins (HDL) Interrupt the Sphingosine Kinase Signaling Pathway. A possible mechanism for protection against atherosclerosis by HDL. J Biol Chem 1999; 274:33143-7.

37. Krishnaswamy G, Kelley J, Yerra L, Smith JK, Chi DS. Human endothelium as a source of multifunctional cytokines: molecular regulation and possible role in human disease. J Interferon Cytokine Res 1999; 19:91-104.

38. Chen X, Xun K, Chen L, Wang Y. TNF-alpha, a potent lipid metabolism regulator. Cell Biochem Funct 2009; 27:407-16.

39. Kario K, Matsuo T, Kobayashi H, et al. High lipoprotein (a) levels in chronic hemodialysis patients are closely related to the acute phase reaction. Thromb Haemost 1995; 74:1020-4.

40. Bray GA. Medical consequences of obesity. J Clin Endocrinol Metab 2004; 89:2583-9.

41. Swan SK. Role of lipids in chronic renal allograft rejection. Contrib Nephrol 1997; 120:62-7.

42. Cottone S, Palermo A, Vaccaro F, et al. In renal transplanted patients inflammation and oxidative stress are interrelated. Transplant Proc 2006; 38:1026-30.

43. Pecoits-Filho $R$, Heimbürger $O$, Bárány $P$, et al. Associations between circulating inflammatory markers and residual renal function in CRF patients. Am J Kidney Dis 2003; 41:1212-8. 